\title{
The Next Generation of High-Speed Dynamic Stability Wind Tunnel Testing (Invited)
}

\author{
Deborah M. Tomek $^{*}$ and William G. Sewall ${ }^{\dagger}$ \\ NASA Langley Research Center, Hampton, Virginia 23681 \\ Stan E. Mason ${ }^{\ddagger}$ \\ Jacobs Sverdrup, Inc., Hampton, Virginia 23666 \\ and \\ Bill W.A. Szchur ${ }^{\S}$ \\ Sierra Lobo, Inc., Hampton, Virginia 23666
}

\begin{abstract}
Throughout industry, accurate measurement and modeling of dynamic derivative data at high-speed conditions has been an ongoing challenge. The expansion of flight envelopes and non-conventional vehicle design has greatly increased the demand for accurate prediction and modeling of vehicle dynamic behavior. With these issues in mind, NASA Langley Research Center (LaRC) embarked on the development and shakedown of a high-speed dynamic stability test technique that addresses the longstanding problem of accurately measuring dynamic derivatives outside the low-speed regime. The new test technique was built upon legacy technology, replacing an antiquated forced oscillation system, and greatly expanding the capabilities beyond classic forced oscillation testing at both low and high speeds. The modern system is capable of providing a snapshot of dynamic behavior over a periodic cycle for varying frequencies, not just a damping derivative term at a single frequency.
\end{abstract}

\section{Nomenclature}

The dynamic stability data presented are referred to the body axis system.

b

Cl

$C_{l p}$

$C_{l \dot{p}}$

$C_{l p}+C_{l \dot{\beta}} \sin \alpha$

$C_{\beta} \sin \alpha-k^{2} C l_{\dot{p}}$

$C_{l \beta}$

$C_{l \dot{\beta}}$

$\mathrm{Cm}$

$\mathrm{Cm}_{q}$

$\mathrm{Cm}_{\dot{q}}$

$\mathrm{Cm}_{q}+\mathrm{Cm}_{\dot{\alpha}}$

$\mathrm{Cm}_{\alpha}$
= wing span

$=$ rolling moment coefficient, (rolling moment $/ q_{\infty} S b$ )

$=\partial C_{l} / \partial(p b / 2 V)$

$=\partial C_{l} / \partial\left(\dot{p} b^{2} / 4 V^{2}\right)$

$=$ damping-in-roll parameter

$=$ rolling moment due to roll-displacement parameter

$=\partial C l / \partial \beta$

$=\partial C_{l} / \partial(\dot{\beta} b / 2 V)$

$=$ pitching moment coefficient, (pitching moment $/ q_{\infty} S c$ )

$=\partial C m / \partial(q c / 2 V)$

$=\partial C m / \partial\left(\dot{q} c^{2} / 4 V^{2}\right)$

$=$ damping-in-pitch parameter

$=\partial C m / \partial \alpha$

\footnotetext{
* Aerospace Engineer, Flow Physics and Control Branch, RTD, Mail Stop 170, Member AIAA.

${ }^{\dagger}$ Aerospace Engineer, Data Acquisition and Data Quality Team, COD, Mail Stop 340.

‡ Systems Engineer, ROME Tactical Engineering, NASA Langley Mail Stop 925.

$\S$ Senior Controls Engineer, ROME ISD, Mail Stop 267.
} 


$\begin{array}{ll}C_{m \dot{\alpha}} & =\frac{\partial C m}{\partial(\dot{\alpha} C / 2 V)} \\ C_{m \alpha}-k^{2} C_{m \dot{q}} & =\text { oscillatory longitudinal stability parameter } \\ C_{n} & \left.=\text { yawing moment coefficient, (yawing moment } q_{\infty} S b\right) \\ C_{n} & =\frac{\partial C n}{\partial(r b / 2 V)} \\ C_{n} & =\frac{\partial C n}{\partial\left(\dot{r} b^{2} / 4 V^{2}\right)} \\ C_{n r}-C_{n \dot{\beta}} \cos \alpha & =\text { damping in yaw parameter } \\ C_{n \beta} & =\partial C n / \partial \beta \\ C_{n \dot{\beta}} & =\frac{\partial C n}{\partial(\dot{\beta} b / 2 V)} \\ C_{n \beta} \cos \alpha+k^{2} C_{n \dot{r}} & =\text { oscillatory directional stability parameter } \\ k & =\text { reduced-frequency parameter, }(\omega c / 2 V) \text { in pitch; }(\omega b / 2 V) \text { in roll and yaw } \\ M & =\text { freestream Mach number } \\ p & =\text { angular velocity of model about } \mathrm{X} \text { axis } \\ \mathrm{PID} & =\text { proportional-integral-derivative } \\ q & =\text { angular velocity of model about } \mathrm{Y} \text { axis } \\ q_{\infty} & =\text { freestream dynamic pressure } \\ r & =\text { angular velocity of model about } \mathrm{Z} \text { axis } \\ S & =\text { reference area } \\ V & =\text { freestream velocity } \\ W L & =\text { water line } \\ \alpha & =\text { angle of attack } \\ \beta & =\text { angle of sideslip } \\ \omega & =\text { angular velocity, } 2 \pi f \\ f & =\text { frequency } \\ & \end{array}$

\section{Introduction}

$\mathrm{N}$

ASA LaRC has recently developed a new generation of dynamic stability test capability for both the low and high-speed flow regimes. Dynamic stability testing is conducted at LaRC wind tunnels encompassing flight envelopes in the subsonic, transonic and supersonic regimes. This specialized test technique determines aerodynamic stability damping coefficients and spring-inertia parameters of a forced oscillating model in the pitch, roll, and yaw modes in addition to acquiring time history data over an oscillatory cycle. The first generation system was designed and built in the 1960s with an electro-mechanical resolver-based analog system. ${ }^{1}$ A large analog motor generator (MG set) was used to drive a sting with very limited load capabilities. In the early 1990's, utilizing the same sting, the instrumentation was upgraded to a DOS PC-based system utilizing digital signal processing boards. ${ }^{2}$ These historical systems were extremely successful in obtaining damping derivative data for nearly 40 high profile programs spanning Mercury ${ }^{3}$, Apollo ${ }^{4}$, the Space Shuttle ${ }^{5}$ and many currently operational fighter aircraft. ${ }^{6}$ Though successful, the growing demands of non-conventional vehicle designs and the expansion of flight envelopes pushed the limits of this past technology. The demand increased for accurate derivative information in the high-speed regime as well as the ability to assess vehicle dynamic behavior outside the bounds of isolated resonant frequencies. With these needs in mind an effort was initiated to design, develop, and test a modern dynamic stability system. Table 1 highlights the major differences between the legacy and the new system. 
Table 1. Legacy System Limitations versus New System Improvements.

\begin{tabular}{|l|l|}
\hline \multicolumn{1}{|c|}{ Legacy System } & \multicolumn{1}{c|}{ New System } \\
\hline DOS based, code-dependent instrumentation & LabVIEW GUI based off-the-shelf instrumentation \\
\hline PC486 166 MHz DOS CPU & P4 Xeon 2.4 GHz CPU with 1.2GHz PXI chassis \\
\hline Low signal to noise ratio & Factor of 10 increase in signal to noise ratio \\
\hline 12 bit digital resolution & 16 bit digital resolution \\
\hline Isolated data point computed at resonant frequency only & Data recorded at resonance and during oscillatory cycle \\
\hline No time history data acquisition & Up to 10 minutes of time history recorded per point \\
\hline No plotting or networking capability & Real time plotting and networking capability \\
\hline Low load capacity sting system & High load capacity two-segment sting system \\
\hline
\end{tabular}

The development of the new system required incorporating emergent technology in the design of software and methodologies for the improvement of dynamic data, and also included the expansion of the aerodynamic load limitations of the system wind tunnel hardware. A larger load capacity sting system was designed, fabricated, and tested. The new sting, in addition to the new instrumentation and software, greatly expanded the operating envelope of the test technique by increasing the range of various critical test parameters, such as angle of attack and Reynolds number, thus making this type of testing more useful in the development phase of flight vehicles. The sting system is accompanied by a programmable servo motor/controller package that can interface with the LabVIEW-based 16-bit data acquisition system.

The unique oscillating balances, incumbent from the legacy system, allow testing in three separate modes: pitch, yaw and roll. The balances measure the input mechanical displacement and the corresponding aerodynamic loads of the test model. The load signals are recorded and then resolved into complex phasors relative to the displacement signal for computation of stability damping derivative coefficients.

The expanded capability to view and store time history data for post-test data processing allows for the extraction of other pertinent dynamic data parameters at varying pitch, yaw, and roll rates, as well as acquiring dynamic derivative parameters at the resonant frequency. Time history records provide the opportunity for post-test analysis of points in unsteady, non-linear flow regimes at high angles of attack and high angular rates.

The system demonstrated its capability during a shakedown test with a $1 / 17^{\text {th }}$ scale-model of a fighter aircraft configuration in the LaRC Transonic Dynamics Tunnel (TDT). Two separate wind tunnel entries were conducted in the TDT utilizing the same wind tunnel model; one test with the legacy system and the other with the new modernized system. LaRC personnel conducted the first test entry utilizing the legacy dynamic stability system in an effort to experimentally determine dynamic derivative data at subsonic and transonic conditions over varying oscillation modes: pitch, yaw, and roll. The second wind tunnel entry was conducted at the TDT utilizing the new Dynamic Stability Research System (DSRS).The data acquired from this test were used to make a point-to-point comparison of data acquired during the new system shakedown entry.

Successful validation of the new dynamic stability test technique in pitch and roll mode was achieved early in the shakedown entry permitting extra time to acquire additional data not previously possible with the legacy system due to system constraints. Since pitch and yaw modes both utilize the same balance, yaw mode testing was not required for successful validation and hence was not included in the test matrix.

The purpose of this paper is threefold. First will be to introduce the new dynamic stability test technique, the DSRS and its associated hardware and software. The second, to present data comparison between classic forced oscillation data acquired with the legacy system with data acquired by the newly developed system. Finally, data acquired utilizing the enhanced system capabilities that provide a snapshot of dynamic data over an oscillatory cycle in subsonic, transonic and supersonic conditions are presented.

\section{Analytical Model of a Forced Oscillation Test}

The LaRC Dynamic Stability Research System employs a technique in which the model is mechanically forced to oscillate in the tunnel air-stream at a fixed amplitude and frequency. The model is forced to oscillate in pitch, yaw, or roll mode at an amplitude of \pm 1 degree for pitch/yaw mode and \pm 2.5 degrees for the roll mode. A variable speed drive motor is utilized to oscillate the test model over a variable frequency range of 1 to $20 \mathrm{~Hz}$. The aircraft test section model is viewed as an equivalent spring-mass-damper system, with damping and spring forces provided 
by the interaction between the aircraft and the surrounding compressible air-stream. A diagram showing the relationship of a spring-mass-damper system with the "aerodynamic" spring-mass-damper system is shown in Fig. 1 . $^{7}$ This combination is modeled as a second order dynamical system, where the aircraft angular displacement is the dependent variable, and the external force or moment is the forcing function. In this type of testing the wind tunnel model is mechanically forced to oscillate sinusoidally at a fixed small-amplitude angular displacement over a range of frequencies, and the dynamic responses of the resultant force and moment are measured.

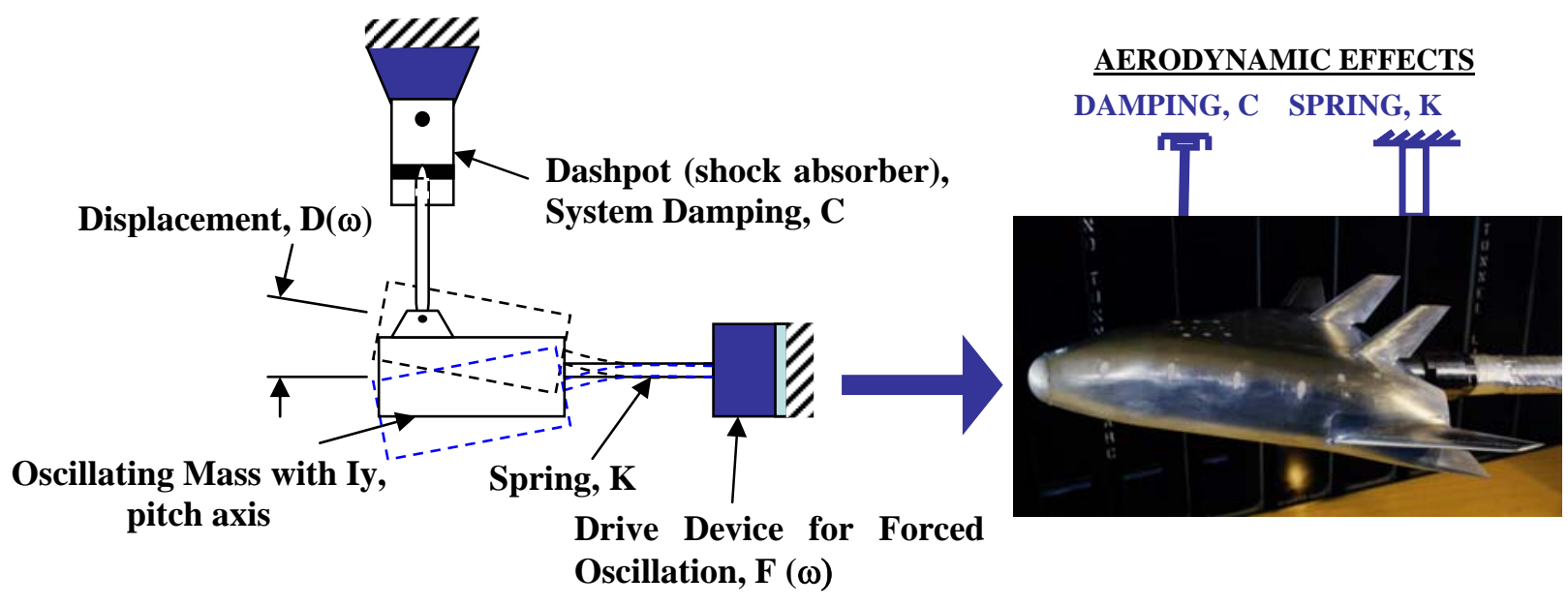

Figure 1. Relationship between Mechanical and Aerodynamic Spring-Mass-Damper Systems.

The differential equation for this system can be expressed as:

$$
I \ddot{D}+C \dot{D}+K D=F e^{i \omega t}
$$

where $I$ is the inertia of the rotating mass, $K$ is the torsional spring constant, $C$ is the damping contribution represented by the dashpot and $F e^{i \omega t}$, an applied force or moment. The mass oscillates with maximum displacement $D$, and at a frequency $\omega$.

The solution to this second order system, from the imaginary component, yields the stability damping coefficient for the torque component:

$$
C=\frac{F \sin \phi}{\omega D}
$$

Similarly, the real components equate to give the spring-inertia parameter:

$$
K-I \omega^{2}=\frac{F \cos \phi}{D}
$$

These equations provide the basis for the computation of the damping derivative coefficients computed from measured values by the DSRS and shown in Table 2 . The data acquired and presented in this paper will focus on the roll and pitch damping parameters. 
Table 2. Stability and Damping Derivative Coefficients.

\begin{tabular}{|c|c|c|}
\hline \begin{tabular}{|l} 
Pitch \\
\end{tabular} & Yaw & Roll \\
\hline $\mathrm{C}_{m_{q}}+\mathrm{C}_{m_{\dot{\alpha}}}$ & $\mathrm{C}_{n_{r}}-\mathrm{C}_{n_{\dot{\beta}}} \cos \alpha$ & $\mathrm{C}_{l_{\mathrm{p}}}+\mathrm{C}_{l_{\dot{\beta}} \sin \alpha}$ \\
\hline $\mathrm{C}_{\mathrm{m}_{\alpha}}-\mathrm{k}^{2} \mathrm{C}_{\mathrm{m}} \dot{\mathrm{q}}$ & $\mathrm{C}_{\mathrm{n}_{\beta}} \cos \alpha+\mathrm{k}^{2} \mathrm{C}_{\mathrm{n}_{\dot{r}}}$ & $\mathrm{C}_{l_{\beta}} \sin \alpha-\mathrm{k}^{2} \mathrm{C}_{l_{\mathrm{p}}}$ \\
\hline $\mathrm{C}_{\mathrm{N}_{\mathrm{q}}}+\mathrm{C}_{\mathrm{N}_{\dot{\alpha}}}$ & $\mathrm{C}_{l_{r}}-\mathrm{C}_{l_{\dot{\beta}}} \cos \alpha$ & $\mathrm{C}_{\mathrm{p}}+\mathrm{C}_{\mathrm{n}} \cdot \sin \alpha$ \\
\hline $\mathrm{C}_{\mathrm{N}_{\alpha}}-\mathrm{k}^{2} \mathrm{C}_{\mathrm{N}} \cdot$ & $\mathrm{C}_{l_{\beta}} \cos \alpha+\mathrm{k}^{2} \mathrm{C}_{l_{\dot{r}}}$ & $\mathrm{C}_{\mathrm{I}_{\beta}} \sin \alpha-\mathrm{k}^{2} \mathrm{C}_{\mathrm{n}_{\mathrm{p}}}$ \\
\hline
\end{tabular}

\section{DSRS Hardware}

As flight envelopes of emergent aircraft and space vehicles have greatly expanded so has the need to update antiquated hardware to fully meet the demanding load and data acquisition requirements. The demand for larger, higher inertia test models has pushed the limits of past technology. These demands dictated the design of hardware that allows testing of larger models in a variety of wind tunnel environments. To meet these requirements the DSRS development involved the design and fabrication of a new high load sting, replacement of the drive motor and control system, and the development of a user-friendly LabVIEW Graphical User Interface (GUI) with expanded digital signal processing techniques. The system allows extensive data acquisition and reduction capability in near real-time.

\section{A. DSRS Sting System}

In order to accommodate the increasing aerodynamic load requirements of current test models a new dynamic stability sting system was designed and fabricated. The DSRS sting mates with balances that mechanically force the wind tunnel model to oscillate at fixed amplitude within a frequency range of $1-20 \mathrm{~Hz}$. The test amplitudes are \pm 1 degree or $\pm 1 / 2$ degree in pitch and yaw mode, and \pm 2.5 degrees in roll mode. The new sting system shown in Fig. 2 has been rated for both air and R134A usage within a temperature range between $50^{\circ} \mathrm{F}$ and $170^{\circ} \mathrm{F}$.

The sting design posed unique requirements in order to enhance load limits yet still maintain the ability to mate with incumbent wind tunnel model support hardware and the dynamic balances. With these goals in mind the sting was designed in two segments. The aft sting segment is designed to handle the maximum aerodynamic loads and to house the high torque motor assembly. The forward segment was designed with a lower load limit, but mates with all the existing oscillating balances. This two-segment design eliminated the need to replace the costly balances at this time but allows for future fabrication of higher load forward segments, without having to fabricate a completely new sting/motor assembly. Table 3 summarizes the sting maximum loads.

The motor drives an internal shaft converting rotary shaft motion to pitch, yaw, or roll motion about the balance oscillation center. Control of the motor RPM is provided by a velocity loop control system. The velocity control is provided using a closed-loop AC synchronous servo system. The closed-loop system is comprised of an AC-driven high-torque servo motor, a high-resolution encoder, and a servo drive. The Data Acquisition System (DAS) rack provides the set point velocity command via a LabView GUI and the servo drive compares this command to the actual encoder feedback and maintains the closed loop thru an internal PID. The servo drive, all control power components, and safety/enable interlocks are housed in the control rack.

Power for the control and DAS racks is supplied by a Mobile Transformer Rack (MTR) that converts two 208 VAC 3-Phase 30 Amp circuits to two 240VAC 3-Phase 30 Amp outlets for the DSRS. The recent addition of the MTR allows greater test technique mobility by eliminating the need for test facilities to install specialized transformers to accommodate the DSRS power requirements. 


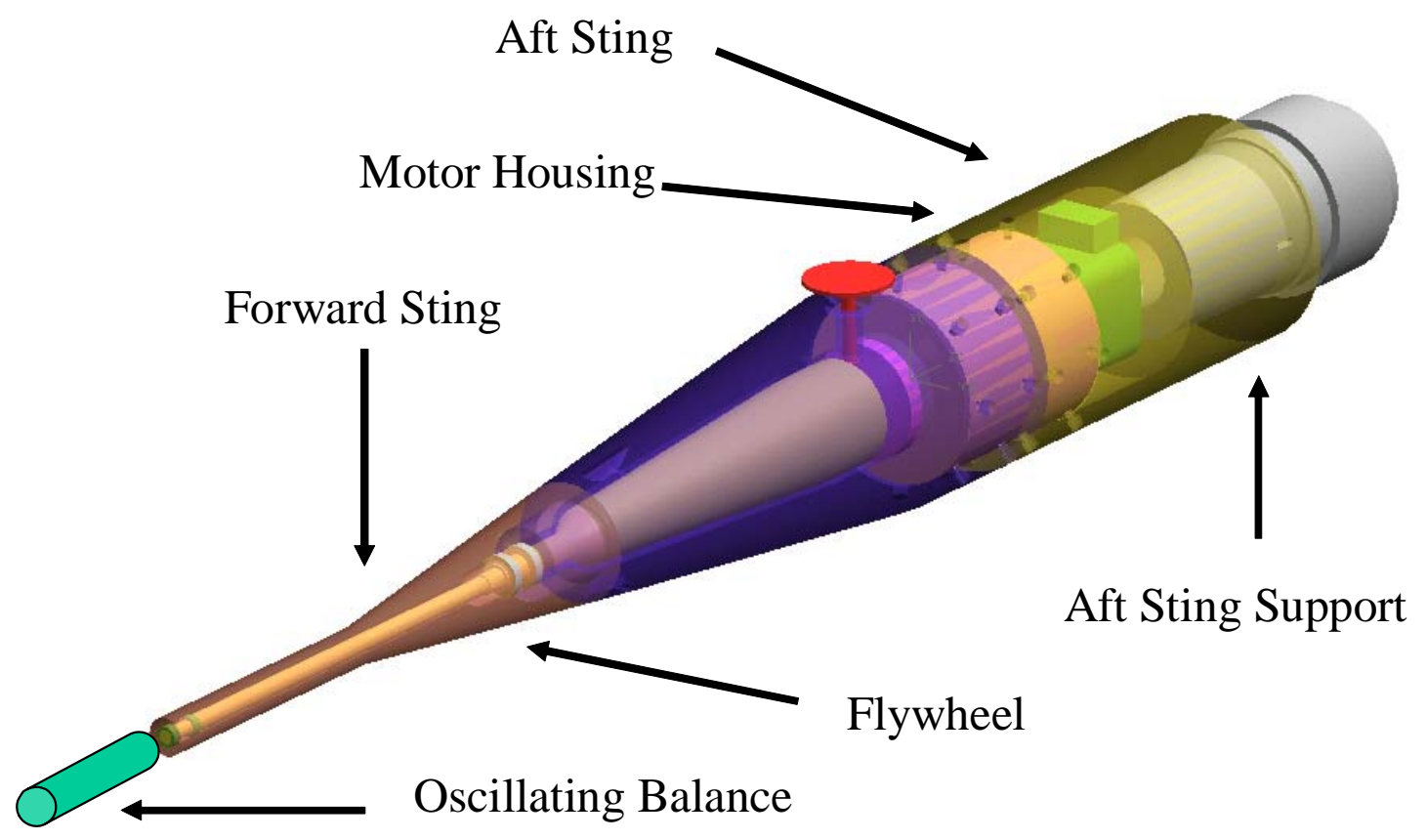

Figure 2. DSRS Two-Segment High Load Sting.

Table 3. Maximum Sting Design Loads

\begin{tabular}{|c|c|c|}
\hline Load Component & Forward Sting & Aft Sting \\
\hline Normal Force & $\pm 2000 \mathrm{lbs}$ & $\pm 7000 \mathrm{lbs}$ \\
\hline Axial Force & $+2000 \mathrm{lbs}$. & $+4500 \mathrm{lbs},-1000 \mathrm{lbs}$ \\
\hline Side Force & $\pm 2000 \mathrm{lbs}$ & $\pm 2000 \mathrm{lbs}$ \\
\hline Pitching Moment & $\pm 6000 \mathrm{in} .-\mathrm{lb}$ & $\pm 5600 \mathrm{ft}-\mathrm{lb}$ \\
\hline Yawing Moment & $\pm 6000 \mathrm{in} .-\mathrm{lb}$ & $\pm 700 \mathrm{ft}-\mathrm{lb}$ \\
\hline Rolling Moment & $\pm 1000 \mathrm{in} .-\mathrm{lb}$ & $\pm 1000 \mathrm{ft}-\mathrm{lb}$ \\
\hline
\end{tabular}

\section{B. DSRS Oscillating Balances}

The only hardware retained from the legacy system are the specially designed oscillating balances utilized to mechanically force the model to oscillate. The balances operate in pitch, yaw, or roll mode. The type of balance used for both the pitch and the yaw tests, GA-16 (Fig. 3), is rolled 90 degrees with respect to the sting to change from pitch mode to yaw mode. The second type of balance, DS-05RC (Fig. 4), is the roll balance. 
These balances, coupled with the unique sting hardware, are employed to measure the input mechanical displacement and the corresponding torque required to oscillate the test model. The angular displacement is measured by means of a strain-gaged mechanical torsion spring while the force and moment load signals are measured by semi-conductor strain gage bridges bonded to the balance beams. Because of the temperature sensitive characteristics of the semi-conductor strain gage, the balances are temperature-controlled with electrical heating elements located at the front and rear of the balance beams. Balance load signals are then resolved into complex phasors relative to the displacement signal for computation of stability and damping coefficients. The new system GUI now incorporates a gage time history module which allows the user to monitor the condition of each balance gage signal. This has already benefited the test process immensely by offering a way to record and monitor thermal drift on the temperature sensitive semi-conductor gages. In recent tests, errors up to $20 \%$ in balance sensitivities have been observed if the temperature across the bridge is not kept constant. This temperature fluctuates based on tunnel temperature and test conditions. Reliance on settling time of balance temperature gradients is costly in terms of tunnel test time. The replacement of these gages with non-temperature sensitive gages (i.e., foil gages) has been considered but the high sensitivity of these gages makes them desirable. As new oscillating balances, with larger load capabilities are fabricated, further consideration of gage type will be investigated.

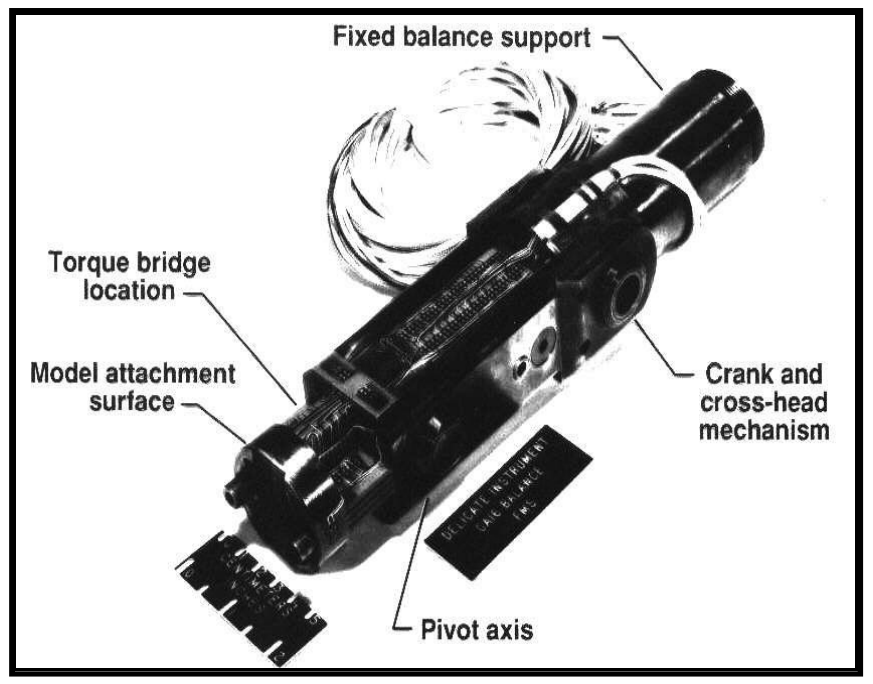

Figure 3. GA-16 Pitch-Yaw Oscillation Balance.

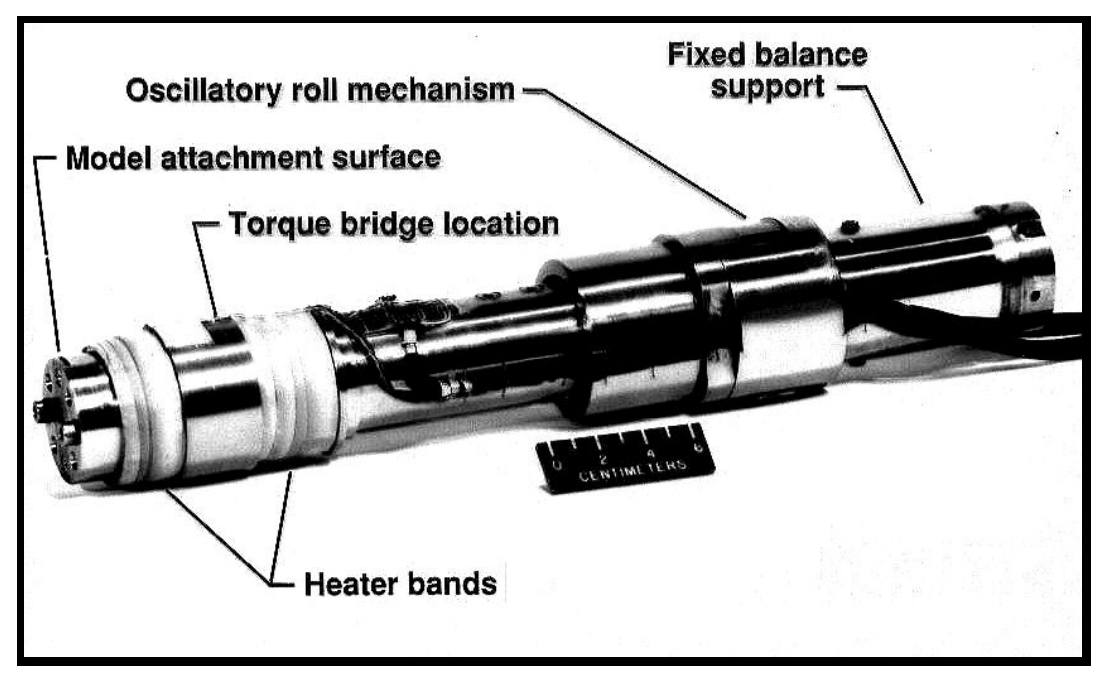

Figure 4. DS-05RC Roll Oscillation Balance. 


\section{Data Acquisition System (DAS) Instrumentation}

The instrumentation system must measure the dynamic amplitudes and relative phase angles of the three primary channels: angular displacement, force (torque) and moment (secondary), as well as drive frequency in order to compute the stability coefficients. The DAS rack houses the majority of the instrumentation required to measure, filter, and record these signals. A block diagram of the system is shown in Fig. 5.

The DSRS is comprised of several hardware components. A crucial component is the signal conditioning system that provides signal amplification and anti-aliasing filters. The sample rate for the system is $2000 \mathrm{~Hz}$ with Butterworth anti-alias filters set at $300 \mathrm{~Hz}$. The signal conditioner system is housed in a rack-mounted chassis containing up to 8 separate electronically coupled, programmable, solid-state instrumentation amplifiers and filters. The signal conditioner chassis is controlled by the PXI system. The PXI system uses Windows 2000 running on an embedded controller. Each of the balance beams (two per balance) is equipped with its own dedicated set of gages to measure the primary and backup displacement, torque and secondary signals. Three additional signal conditioners are used to measure these "backup" gage signals whose sole purpose is to monitor instantaneous balance loads. The legacy system did not have instantaneous load monitoring capability and could not determine when balance load limits were being exceeded at unsteady flow conditions. The incorporation of load monitoring capability during the test phase is an enhanced safety feature of the new system. The workstation is a $2.4 \mathrm{GHz}$ Xeon processor running Windows 2000. The workstation runs the custom software written as a client to the PXI system running across a 100base-T network connection.

The DSRS has been designed to allow maximum mobility for testing in any facility that meets programmatic and customer needs. Modifications are continuing to be made to emphasize portability. For example, the DAS rack contains a signal conditioning circuit for an angle-of-attack sensor when the DSRS system controls the angle of attack. Also, an existing sting used for testing in the LaRC Unitary Plan Wind Tunnel (UPWT) is being modified to interface with the DSRS. The modified sting continues the capability of forced oscillation testing into the supersonic regime. Taking into account test section size, model hardware and load considerations the DSRS can be installed in numerous test facilities encompassing a large flight condition envelope. 


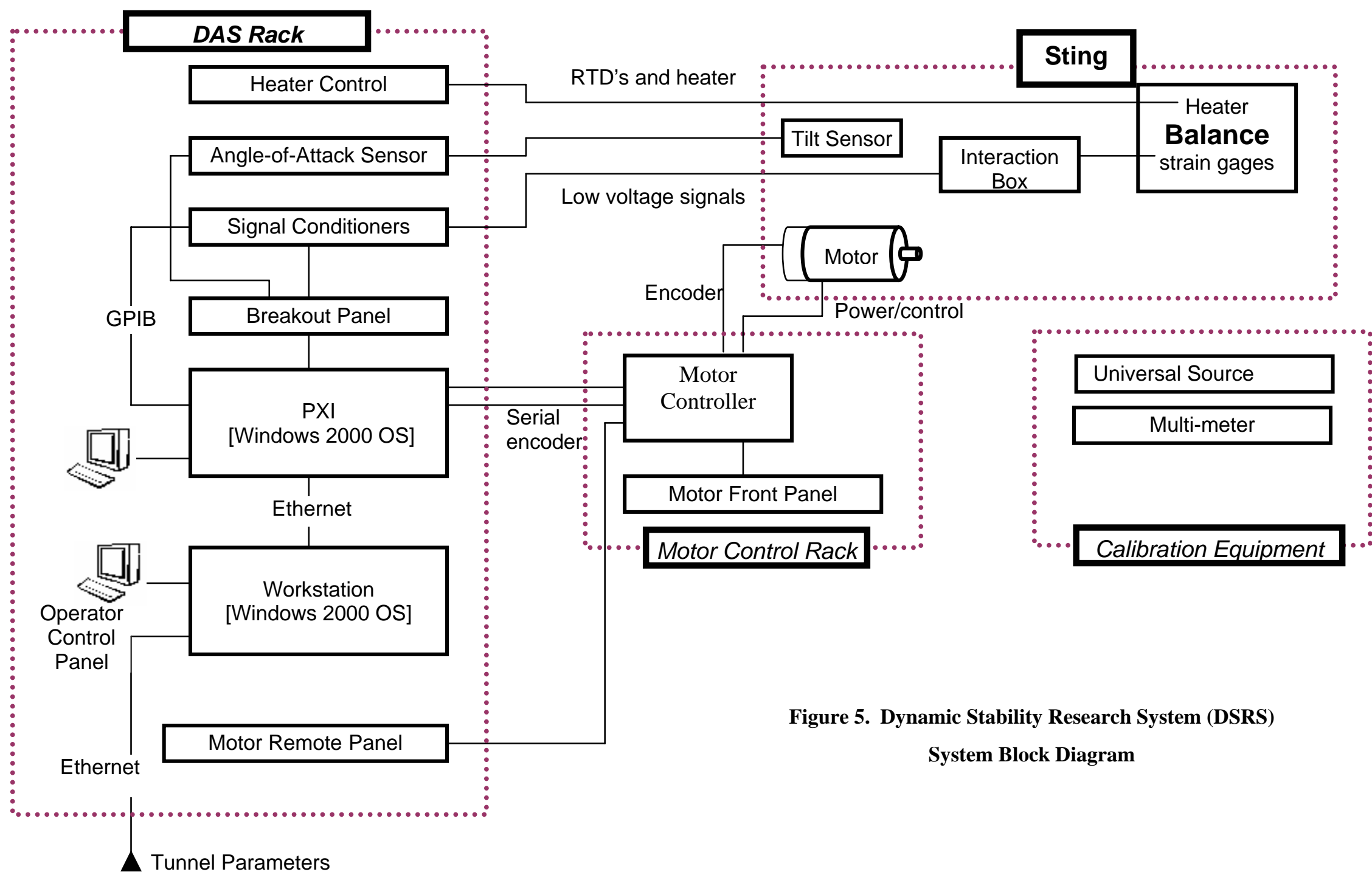




\section{DSRS Software Structure}

The new DSRS custom software incorporates the use of LabVIEW real-time module programs on both client (workstation) and host (PXI system) computers. This two-PC system serves as an operating system manager, provides a user-friendly Graphical User Interface (GUI), displays pertinent test parameters (i.e., spectral plots, load monitoring, tunnel conditions), displays final computed coefficients in real time, records all raw time history data, and controls all peripheral devices.

The system was designed for two PCs to isolate real-time functions, such as data recording, from operator interactions, thereby enhancing system reliability. The custom program, Dynamic Stability Algorithm and Control (DSAC), running on the PXI System controls all hardware and equipment while acting as a host server to the workstation. Raw data acquisition, algorithm processing, system controls, and automation are devoted to the host computer while the client computer offers network communication with the tunnel data system. In addition, the client computer GUI displays real-time computed data, time histories, and balance loads. Table 4 describes how the functionality is split between the two PCs.

\section{Table 4. Functionality between the Workstation and the PXI}

\begin{tabular}{|c|c|}
\hline PXI (Host) & Workstation (Client) \\
\hline $\begin{array}{l}\text { - Sends and receives commands from the } \\
\text { servo motor system } \\
\text { - } \quad \text { Reads in the encoder data through digital } \\
\text { inputs } \\
\text { - Sends commands to the signal } \\
\text { conditioners } \\
\text { - } \text { Digitizes conditioned strain gage voltages } \\
\text { through analog inputs } \\
\text { - } \quad \text { Performs the demodulation of the signals } \\
\text { - } \text { via } 100 \text { Base-T Ethernet } \\
\text { Receive and act on commands from the } \\
\text { workstation (to control the signal } \\
\text { conditioners, servo system and the digital } \\
\text { filtering) } \\
\text { Run the PXI GUI (mainly for system } \\
\text { development, debugging and monitoring) }\end{array}$ & $\begin{array}{l}\text { - } \text { Runs Main Test GUI } \\
\text { - } \text { Receive high-speed data from PXI via } \\
\text { 100Base-T Ethernet } \\
\text { - Receive tunnel parameter data from test } \\
\text { facility } \\
\text { - Perform final data analysis and } \\
\text { computations } \\
\text { - Display dynamic derivative data, time } \\
\text { history data, spectral charts, and balance } \\
\text { loads to the operator } \\
\text { - Data storage }\end{array}$ \\
\hline
\end{tabular}

The LabVIEW software structure for the DSRS is a modular based program. The main module (Main Test GUI) initializes the system and presents the user with a set of other modules to run, either sequentially or in parallel. Main Test GUI provides the software interface, so the operator can control the DSRS system. Each module is as independent as possible - with its own global variables and functions. This provides the ability to create, debug, and edit each module with minimal impact on the rest of the code. Figure 6 shows the display window for the Main Test GUI containing all the pertinent test modules. 


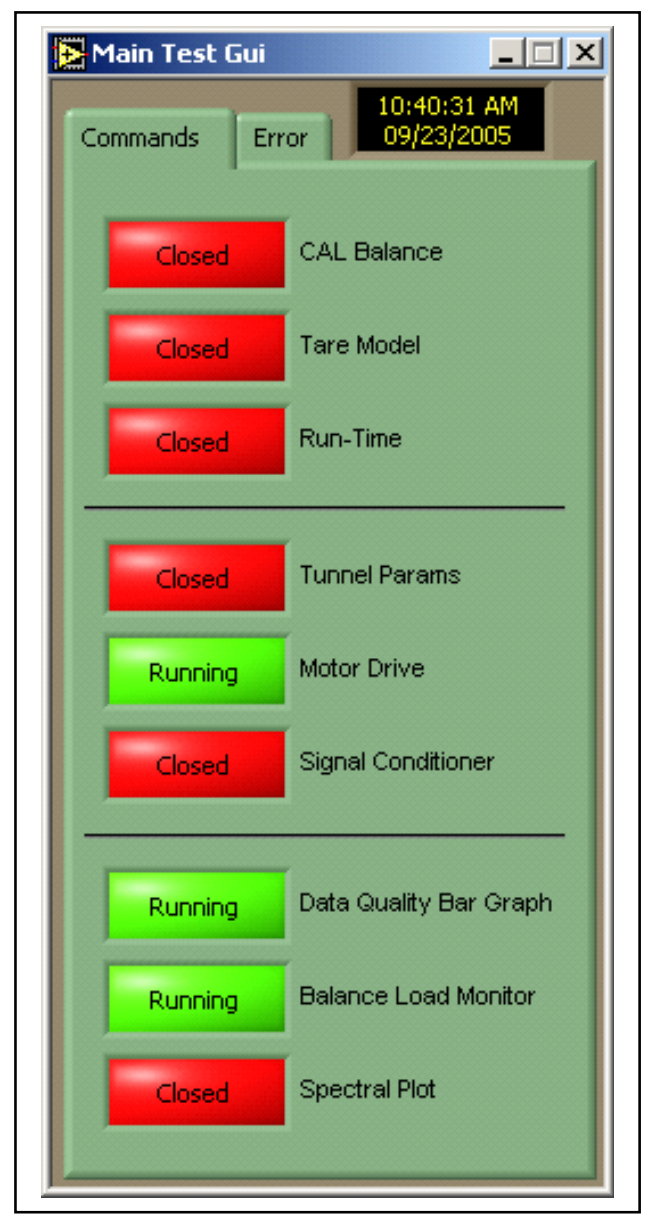

Figure 6. Main Test GUI Display Window.

The DSRS can presently store raw data along with the motor drive system status reports and algorithm calculated statistics for each point recorded. Ten minutes of raw data is the maximum record length the existing hardware can support due to CPU and memory limitations of the workstation. The recorded time history data allows for extensive post-test data reduction capabilities. The PXI software will manage the hardware timing for the data acquisition, while maintaining communications to the sting motor drive system and the signal conditioners The PXI system digitizes the balance and encoder data at 2000 samples a second. This balance data is then demodulated based on the balance position measured by the encoder. This demodulated data is then filtered and packaged into $1 / 2$ second blocks of data with the raw balance and encoder data. These $1 / 2$ second blocks of data are then available via Ethernet to the client program, Main Test GUI, on the workstation.

Because of unsteady aerodynamic flow and support mechanism vibration the response of the model can be corrupted by wide-band noise of a nearly uniform power spectrum. Extensive narrow-band filtering is required to reject all of the dynamic energy in the force and moment signals except that portion at the resonant or forcing frequency. The displacement signal, though not noisy, undergoes the same filtering in order to preserve phase relationships. The system algorithm is a time domain approach utilizing a numerical complex synchronous demodulation technique. The synchronous demodulation algorithm can provide the needed spectral resolution required to extract just that portion of the signal at the drive frequency essentially acting as a very narrow band pass filter. The synchronous demodulation algorithm is described in Tripp and Tcheng. ${ }^{2}$ 


\section{DSRS Shakedown Test Approach}

The shakedown test was conducted with a $1 / 17^{\text {th }}$ scale-model of a fighter aircraft configuration in the LaRC TDT. Two separate wind tunnel entries were conducted utilizing the same wind tunnel model for data comparison between the legacy and new systems. LaRC personnel conducted the first test entry utilizing the legacy dynamic stability system to determine dynamic derivative data at subsonic and transonic conditions over varying oscillation modes: pitch, yaw and roll. This second wind tunnel entry was conducted at the same conditions utilizing the new dynamic stability system software and hardware.

The data obtained with the legacy system served as the baseline for the data acquired during the new system shakedown entry. As stated earlier, the new system algorithm utilizes the same methodology for each mode in the acquisition and filtering of the dynamic signals and varies only in the final coefficient computations. The majority of data acquired during the baseline entry focused on roll and pitch damping characteristics of the fighter configuration, therefore the shakedown matrix was mainly dominated with runs in the roll and pitch modes as shown in data discussed in Section VI.

\section{A. Test Facility}

The facility used was the NASA Langley Research Center Transonic Dynamics Tunnel. The TDT is a closedcircuit, continuous flow, variable pressure wind tunnel with a 16 -ft square test section with cropped corners. The tunnel is capable of using either air or R-134a as the test medium. The tunnel can operate up to a Mach number of 1.2 and is capable of maximum Reynolds numbers of about $3 \times 10^{6}$ per $\mathrm{ft}$ in air and $10 \times 10^{6}$ per $\mathrm{ft}$ in R-134a. The tunnel may also be operated at stagnation pressures from near vacuum ( 0.025 atms) to atmospheric and at dynamic pressures up to 330 psf in air and 550 psf in R-134a. A schematic of the tunnel is shown in Fig. 7.

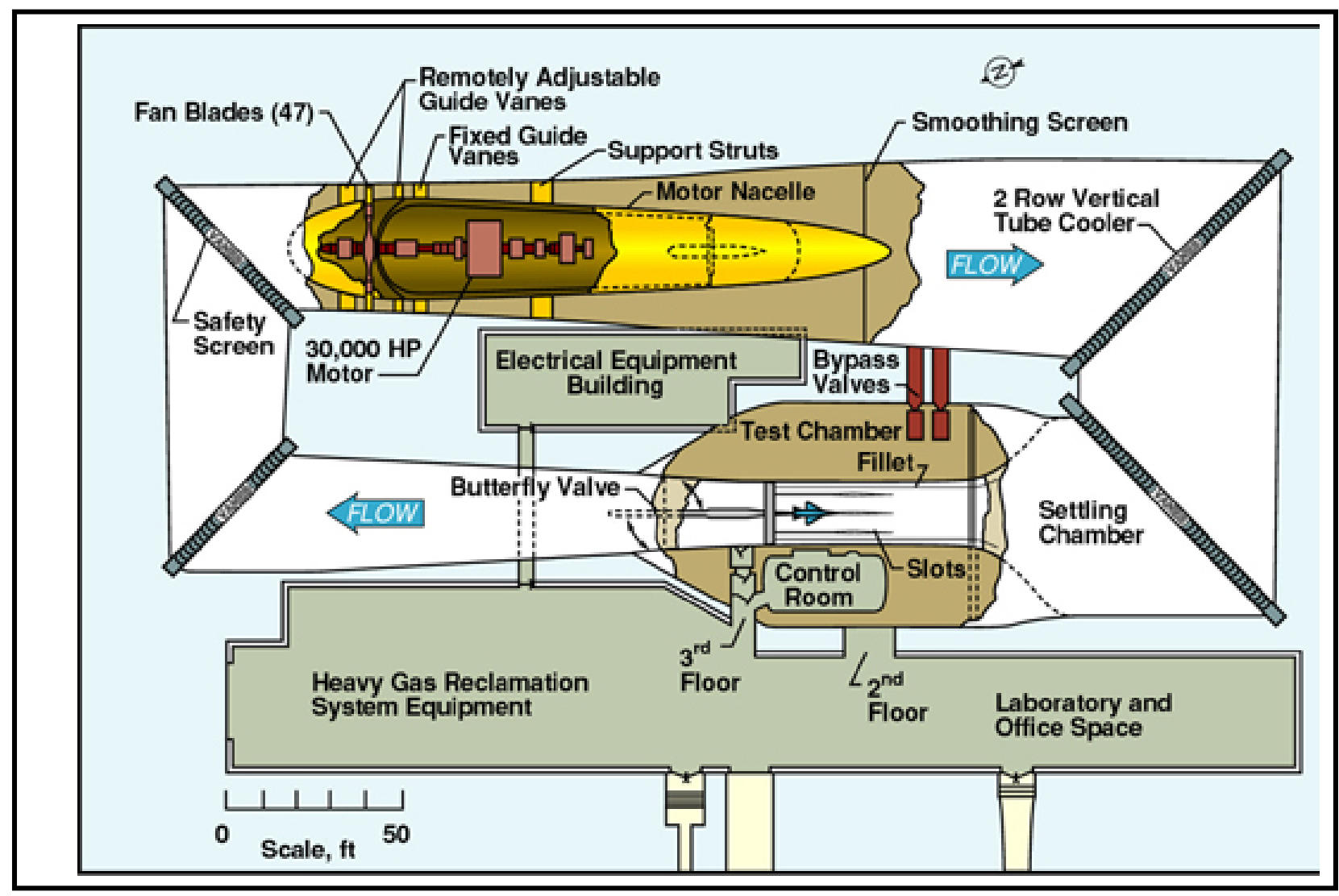

Figure 7. Transonic Dynamics Tunnel (TDT) Schematic. 


\section{Wind Tunnel Test Model}

The model installed in the TDT can be seen in Fig. 8. It was designed to meet the mass properties parameters driven by the dynamic balance torsion spring. The design of models for forced oscillation testing can be challenging because the model is constrained by balance driven inertia limits forcing the model mass to be low, yet still be of substantial strength to withstand the aerodynamic loading conditions experienced during tunnel testing. This model was designed with a combination of materials consisting of both composites and metals. The model strong-back and the bulkheads were all fabricated from Aluminum $6061 \mathrm{~T}$, while the fuselage and the inlets are both a fiberglass composite. The balance adapter, being in the critical load path, is fabricated from Stainless Steel 15-5. The combination of materials kept the model lightweight and well within the system inertia limits. Over 10 configurations exist for this test model varying with control surface areas, flap schedules and store combinations. For clarity only 3 configurations are discussed. The first two configurations, A and F, consist of the same control surface areas yet vary in leading edge flap schedules. Configuration $\mathrm{K}$ has smaller control surface areas. Fig. 9 shows the model in Configuration $\mathrm{K}$ with full stores. The balance had 0.0 deg incline relative to the model $W L=0$. The reference length for the pitching moment coefficients is the mean aerodynamic chord, $c$. For the yawing and rolling moment coefficients the reference length is the wing span, $b$. The reference values for each model configuration used for coefficient computation are shown in Table 5.

Table 5. Model Reference Length for Coefficient Computation

\begin{tabular}{|c|c|c|c|}
\hline Model Configuration & $\begin{array}{c}\text { Chord Length, mac } \\
(\mathbf{f t})\end{array}$ & $\begin{array}{c}\text { Wing Span, b } \\
(\mathbf{f t})\end{array}$ & $\begin{array}{c}\text { Reference Area, } \boldsymbol{S} \\
\mathbf{( f t}^{\mathbf{2}} \mathbf{)}\end{array}$ \\
\hline $\mathbf{A}$ & 0.9823 & 2.529 & 2.1453 \\
\hline $\mathbf{F}$ & 0.9823 & 2.529 & 2.1453 \\
\hline $\mathbf{K}$ & 0.8706 & 2.059 & 1.5917 \\
\hline
\end{tabular}

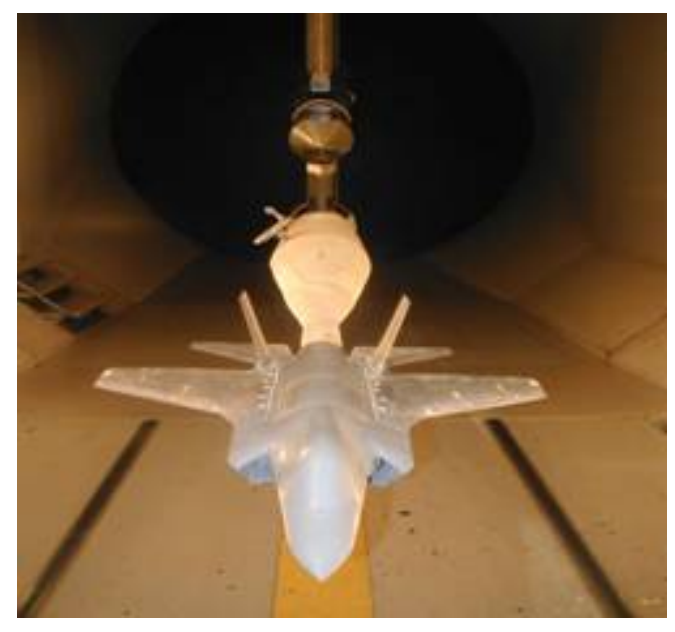

Figure 8. Test Model installed in the TDT

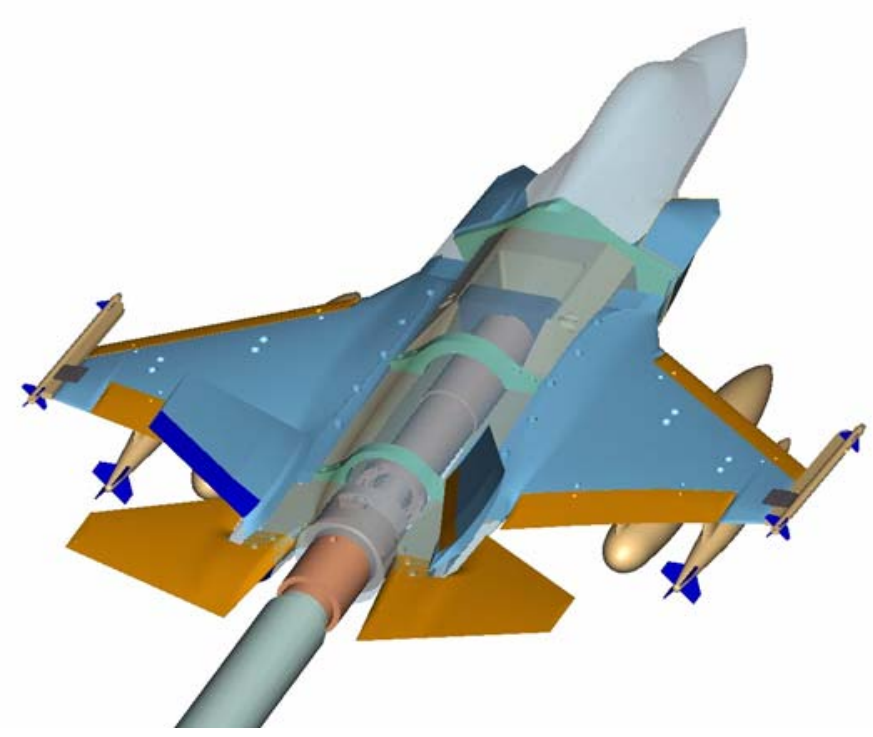

Figure 9. Test Model shown with Balance/Sting Mount 


\section{DSRS Shakedown Data Summary}

The series of tests to verify the DSRS were conducted for various fighter configurations over a Mach number range of 0.2 to 1.16 measuring pitch and roll damping, as well as the normal force due to pitch rate and the cross derivative yawing moment due to roll rate. The test angle of attack range was from -2.5 to 27.5 degrees. The forced oscillation portion of the test was conducted mainly to acquire the damping parameters, pitch damping $C_{m_{q}}+C_{m_{\dot{\alpha}}}$ and roll damping $C_{l_{p}}+C_{l_{\dot{\beta}}} \sin \alpha$. Due to the propriety nature of the fighter configuration all data are shown with ordinate axes labels removed. The data are for system verification purposes only and the stability characteristics of the test model are not discussed. The main focus of the first tunnel entry was assessment of roll damping qualities of the fighter aircraft; therefore, the development of the test matrix for the second shakedown entry was centered about making comparisons with the roll damping parameter. System validation was also completed in pitch mode for one model configuration. The DSRS data acquisition and reduction scheme utilizes the same algorithm for each mode and only the final coefficient computations vary with the desired parameter, therefore yaw mode validation was not conducted. The various configurations represented in the data reflect flap angle settings and control surface areas which will be represented generically. The data for both entries are plotted together for clarity.

Data from the first test entry revealed that the complex aerodynamic flow field experienced at transonic, high angle of attack conditions led to periods of increasing instability in the high alpha range. As the damping data approached neutral stability the minimal damping values were very difficult, if not impossible, to extract from the wideband noise spectrum with the legacy system. The signal to noise ratio (SNR) of the legacy system, a factor of 10 lower than the new system, was unable to boost the dynamic signal from the noise floor. Additional constraints during the first entry were the load limits imposed by the old sting and sting deflections resulting in an overload on the secondary signal, yaw due to roll. Thus the legacy system was unable to acquire many of the desired transonic, high angle of attack data points during the first test entry. With the improvement of SNR by a factor of 10 and the fabrication of the higher load capacity sting, the DSRS was able acquire all of these increasingly unstable data points. In addition, the new system was able to acquire simultaneous time history data while oscillating in the pitch and roll modes. The acquisition of the time history data provides opportunity for extensive post-test analysis of unstable points in the high angle of attack and high angular rate regimes in addition to allowing for alternate methods of data reduction and formulation.

\section{A. Comparison of Classic Forced Oscillation Data}

Roll damping data for Configuration $\mathrm{K}$ of the model over various Mach numbers are shown in Fig. 10. These plots show comparison damping derivative values between the new system and the legacy system. The results obtained from the two systems are very similar at low alphas across the given Mach range. Figure 11 shows the roll damping for Configuration A over a higher Mach range and higher alpha. Figure 11(a) confirms earlier conclusions of good data repeatability in the lower Mach while displaying how this carries through into the higher angle of attack range. Figure 11(b) demonstrates results due to the improved design of the DSRS software and sting hardware; we were able to extract small damping values at difficult transonic, high alpha points. These data were previously not obtainable with the legacy system due to low signal levels and sting hardware constraints. With the new ability to acquire this type of highly unstable data we were able to greatly expand the test matrix to fill in data sets. Figure 11(c) shows an unsuccessful trend match in data at Mach 0.95. This poor match could be due to the difficulty acquiring the baseline data in the first entry at these conditions. Therefore, a higher level of data integrity has been assumed with the new system data. 
M0.2

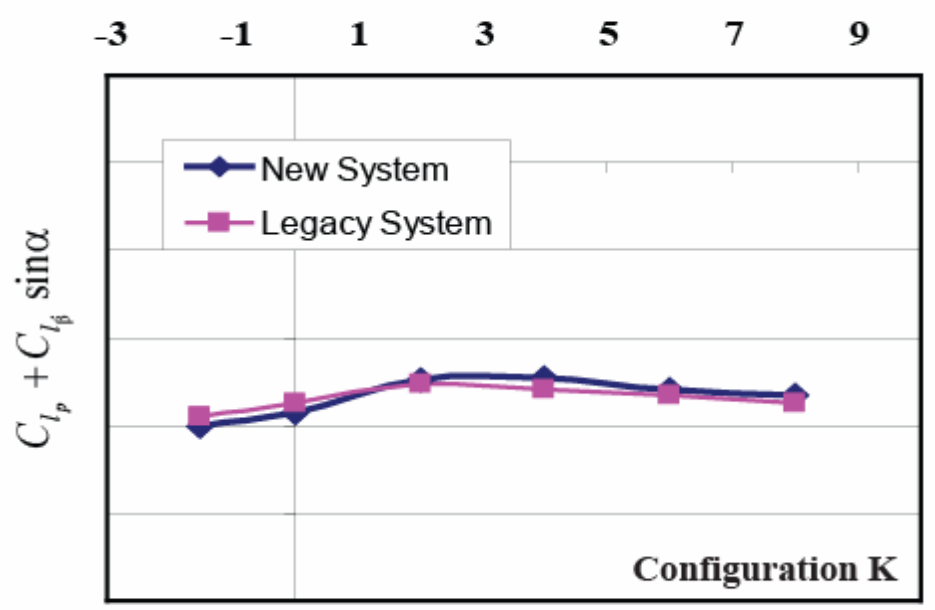

(a)

Angle of Attack, Deg
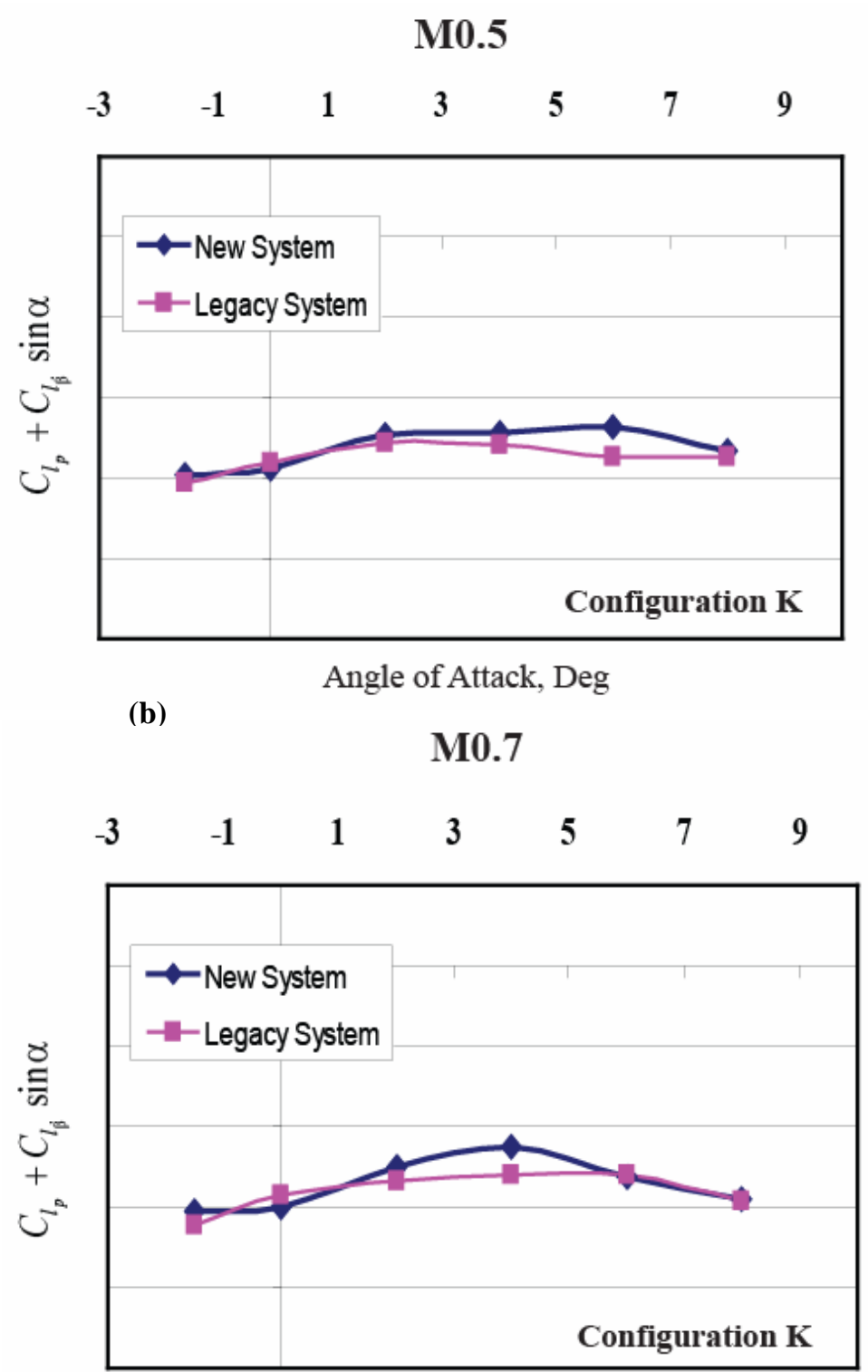

Angle of Attack, Deg

(c)

Figure 10. Roll Damping Parameter, Configuration $\mathrm{K}$

American Institute of Aeronautics and Astronautics 


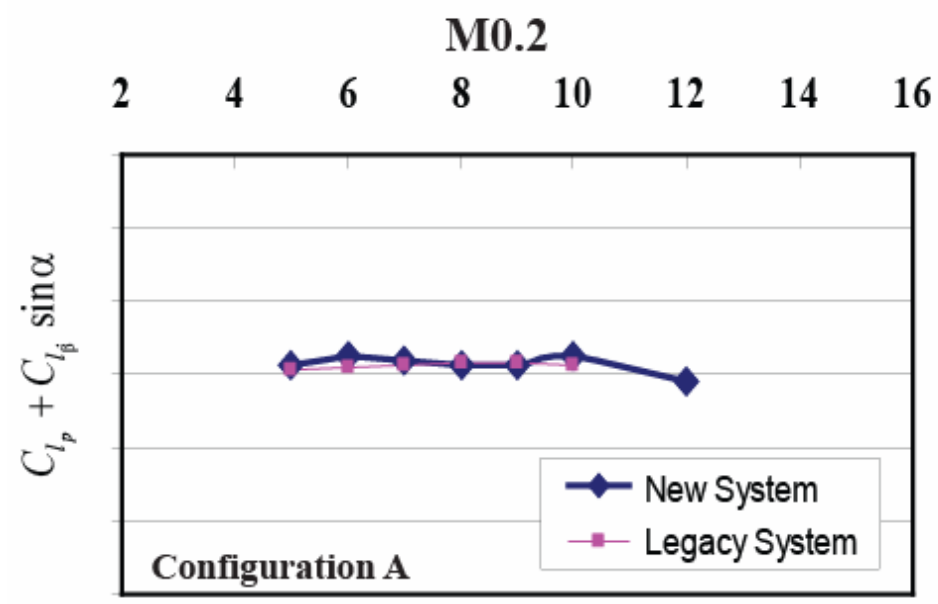

(a) Angle of Attack, Deg

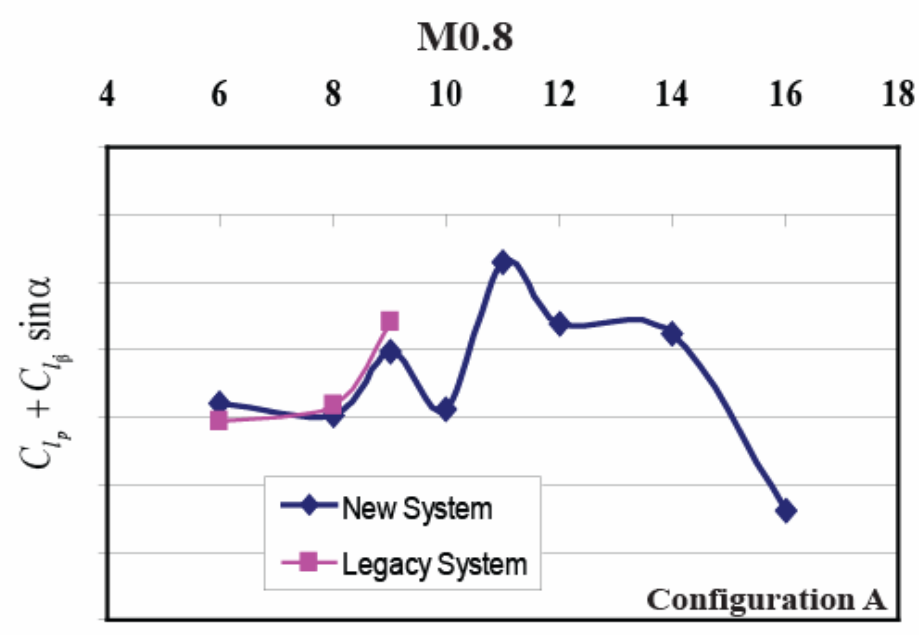

(b)

Angle of Attack, Deg

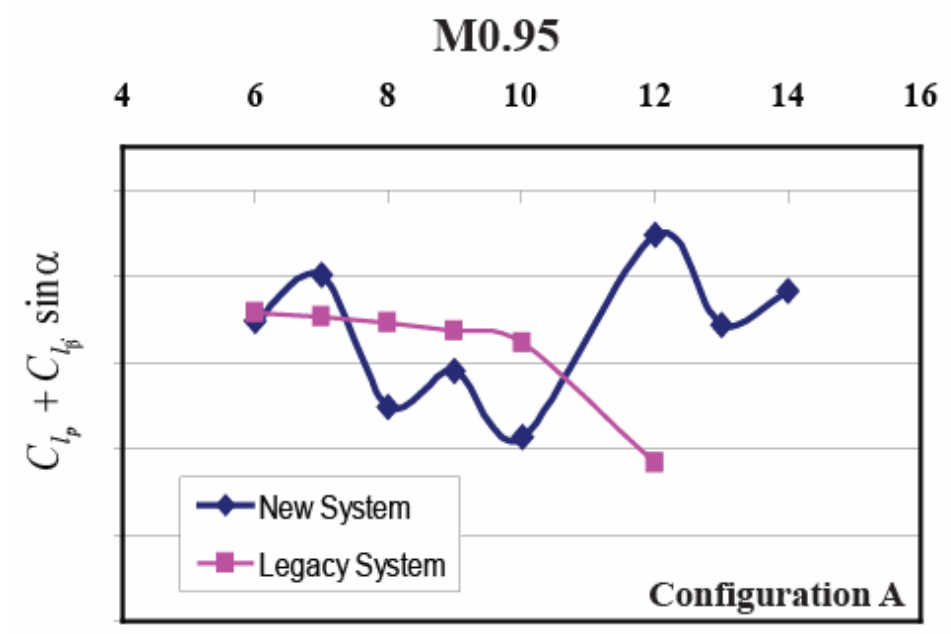

(c)

Angle of Attack, Deg

Figure 11. Roll Damping Parameter, Configuration A 
The data shown in Fig. 12 are another example of the expanded capability possible with the new hardware and software. The previous system was only able to obtain data at three alphas before secondary load limits were exceeded. The new system was able to acquire data across the whole desired alpha range. This was possible since the new sting was a better fit with the roll balance. This prevented overload conditions seen on the legacy system. Additionally, the improved accuracy of the new data system allowed measurements of lower values of roll damping which could not be acquired by the legacy system.

M0.7

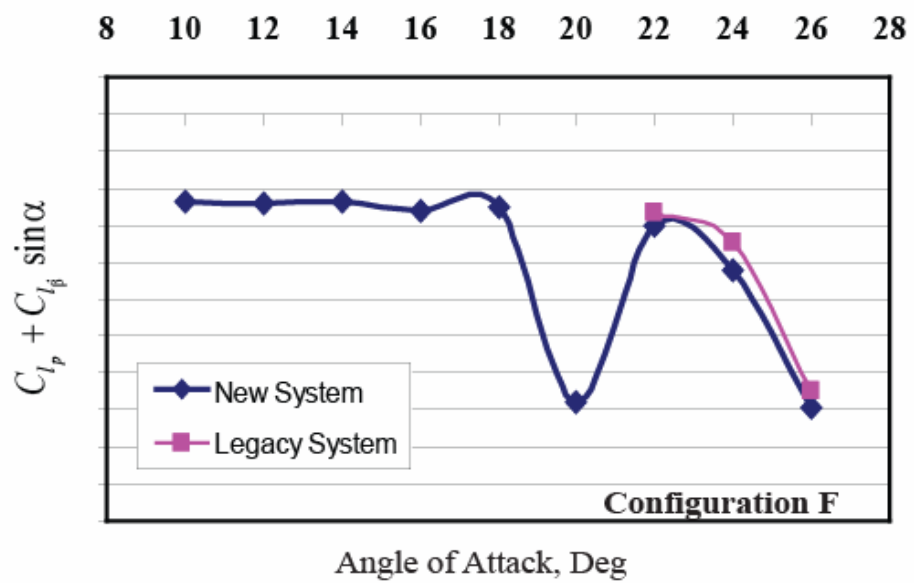

Figure 12. Roll Damping Parameter at M0.7 Demonstrating Extended Data Capabilities

Fig. 13 shows the demonstrated ability to match data in the oscillating pitch mode. This plot shows a very good comparison along the data trend with some deviation in the higher alphas. Some possible reasons why the trend lines deviate in the higher angles could be related to the difficulty acquiring these points with the legacy system and the on-set of flow nonlinearities as the model crossed over the designed flap schedule that is required to fly this aircraft at these alphas.

M0.2

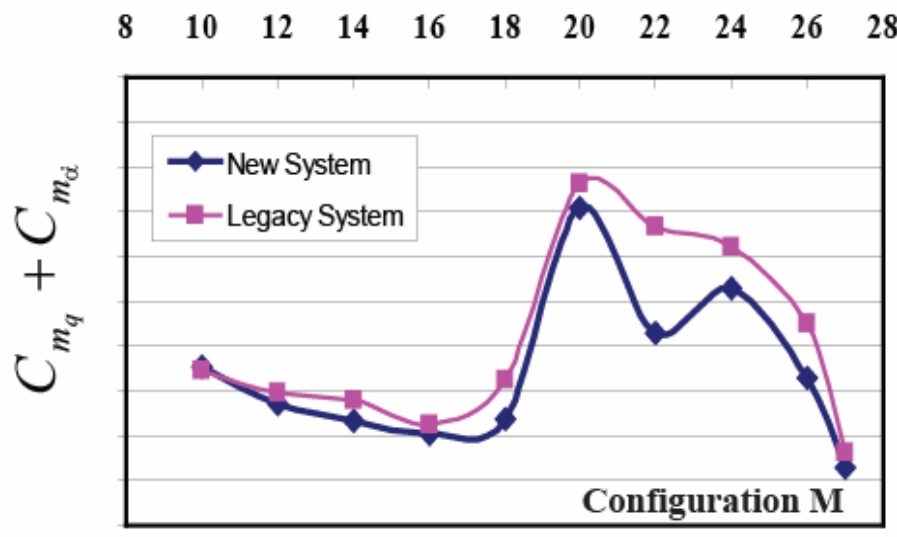

Angle of Attack, Deg

Figure 13. Pitch Damping Parameter 


\section{B. Damping Moment Response Data/Enhanced Data Capabilities}

The data shown in Fig. 14 and Fig. 15 represent the enhanced capability to capture the non-linear rate effects of the model caused by complex aerodynamics. The graphs show rolling moment response over a \pm 2.5 degree roll amplitude for a transonic condition at angle of attack of zero degrees. The plots are shown at two different reduced frequency parameters, $k$. Data were acquired at varying reduced frequency parameters up to $k=0.152$ which equates up to an oscillation frequency of $17 \mathrm{~Hz}$ at Mach 0.8. Data reduction methodologies for this new data type are being developed and analysis will be the subject of future reports. When reduction methodologies are finalized these data will provide a snapshot of periodic model behavior over an oscillatory cycle and address the long standing problem of modeling and understanding dynamic behavior in high-speed flow regimes.

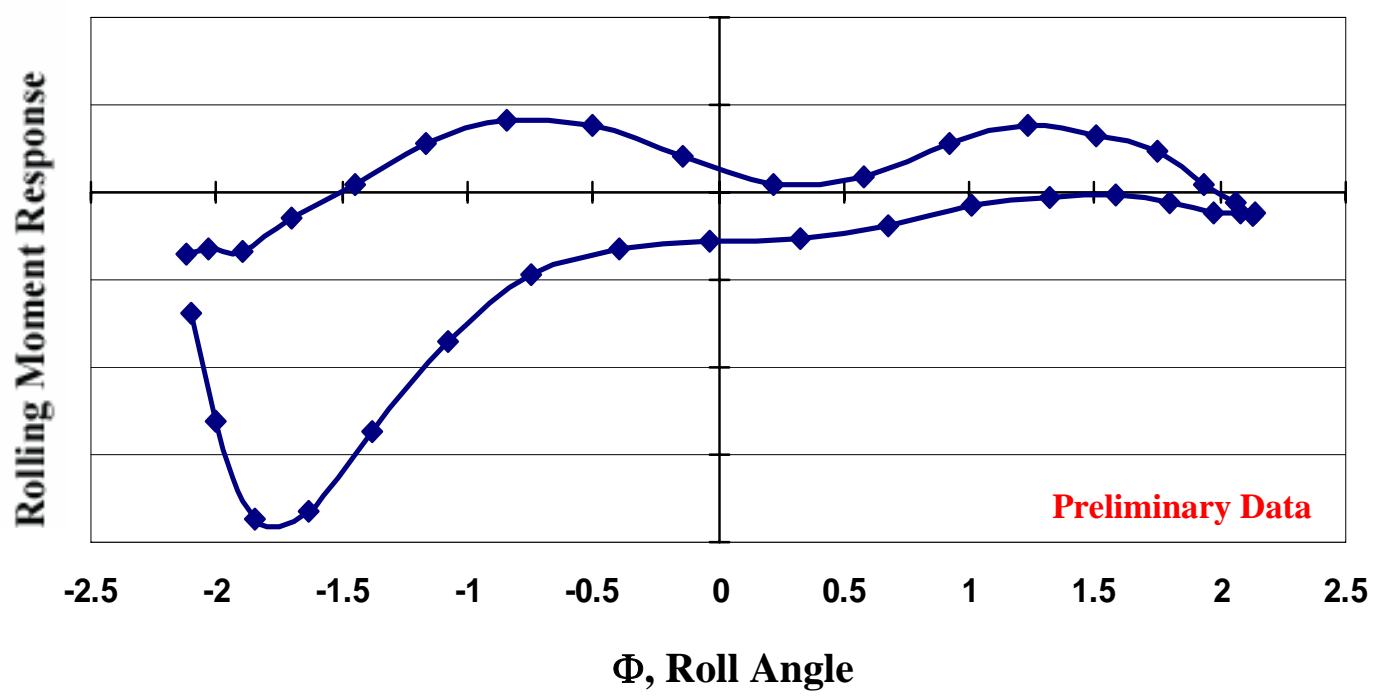

Figure 14. Rolling Moment Response at Mach 0.8, $\alpha=0.0$ degrees, $\boldsymbol{k}=0.045$

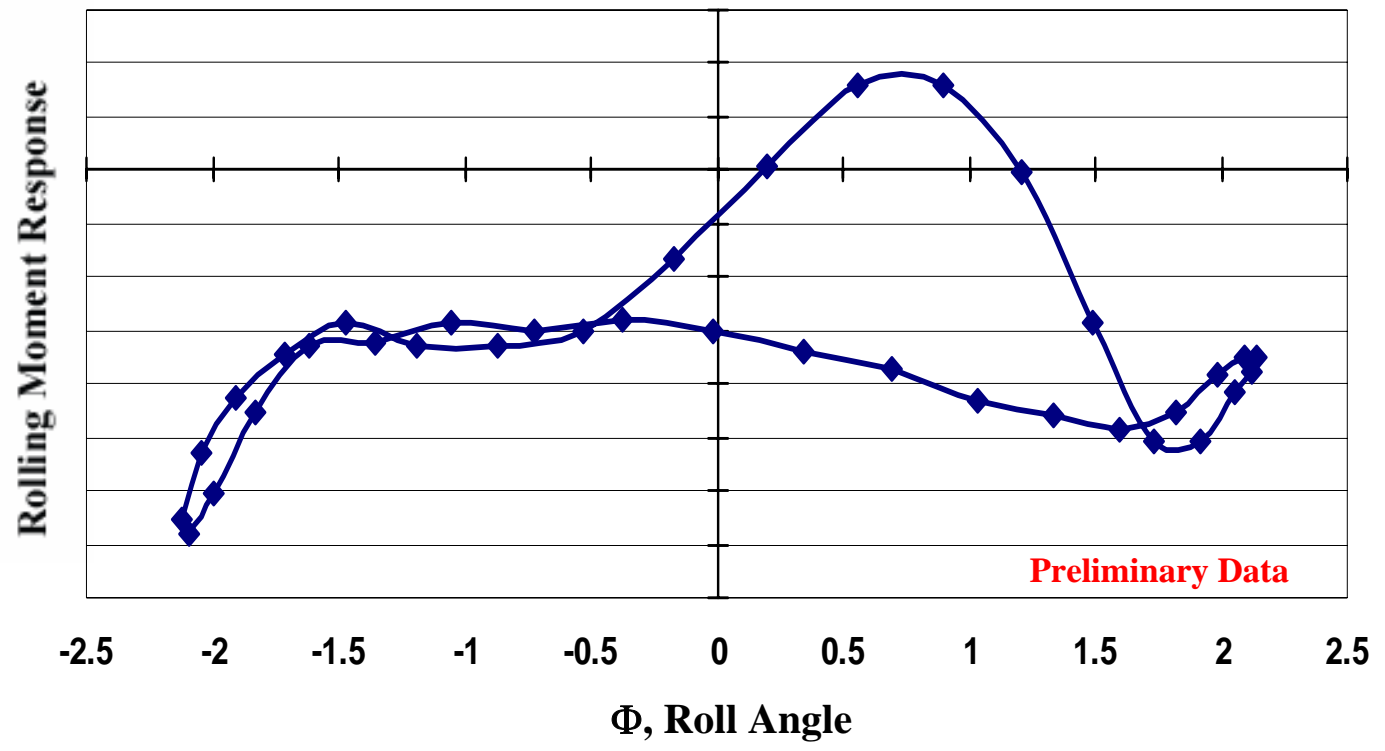

Figure 15. Rolling Moment Response at Mach 0.8, $\alpha=0.0$ degrees, $k=0.067$ 


\section{Conclusions}

The new DSRS captures non-linear rate effects caused by complex aerodynamics and also captures periodic model behavior at high risk, unsteady aerodynamic conditions. The new system also maintains the classic forced oscillation test capability. The combination was realized by developing new hardware and signal processing software that allows data acquisition and storage at highly unsteady flow conditions. The DSRS is the first test technique that has proven capable of acquiring a snapshot of dynamic behavior over a periodic cycle in the subsonic, transonic and supersonic regimes. This is an extension beyond the legacy approach where just a damping term at its respective resonant frequency was obtained.

The development of the new DSRS has enabled the acquisition of dynamic data previously unattainable in transonic and supersonic conditions due to lack of technology and tool development. Though data reduction methodology development is ongoing, initial data sets confirm the ability to acquire "specific point" data at varying angular rates in pitch, roll, and yaw in both low and high-speed regimes. The ability to populate a database with specific angular rate data can provide much higher fidelity vehicle simulations in high speeds during design and prior to flight test stages. This type of dynamic data acquisition, having previously only existed in the low speed realm, now bridges the long-standing gap that has existed in the transonic and supersonic flight regimes. This new test technique eliminates the need to simulate and extrapolate dynamic aerodynamic terms in high-speed flow regimes and is an important step forward in the support of experimental databases for unsteady aerodynamic computational simulations in both high and low speeds.

\section{References}

${ }^{1}$ Wiley, H. G.; and Braslow, A. L., “A Method of Accurately Measuring Dynamic Stability Derivatives in Transonic and Supersonic Wind Tunnels”. Presented to Specialists Meeting on Aircraft Stability and Control of AGARD, Brussels, Belgium, April 10-14, 1961. AGARD Report 345, April 1961.

${ }^{2}$ Tripp, J. S.; and Tcheng, P., “Aerodynamic Stability Test Instrumentation Using Digital Signal Processing Techniques”. AIAA Paper No. 94-2583, Presented at 18th Aerospace Ground Testing Conference, June 20-23, 1994, Colorado Springs, Colorado.

${ }^{3}$ Igoe, William B.; and Hillje, Ernest R., “Transonic Dynamic Stability Characteristics of Several Models of Project Mercury Capsule Configurations”. NASA TM X-554, August 1961.

${ }^{4}$ Averett, B. T.: Dynamic Stability Characteristics in Pitch of Models of Proposed Apollo Configurations at Mach Numbers from 0.30 to 4.63. NASA TM X-1127, August 1965.

${ }^{5}$ Boyden, R. P.; and Freeman, D. C., Jr., "Subsonic and Transonic Dynamic Stability Derivatives of a Modified 089B Shuttle Orbiter”. NASA TM X-72631, 1974.

${ }^{6}$ Kilgore, R. A., "Some Transonic and Supersonic Dynamic-Stability Characteristics of a Variable-Sweep Wing Tactical Fighter Model”. NASA TM X-2163, February 1971.

${ }^{7}$ Tomek, D. M.; Boyden, R. P., “Subsonic and Transonic Dynamic Stability Characteristics of the X-33”. AIAA paper No. 2000-0266, Presented at 38th AIAA Aerospace Sciences Meeting, January 10-13, 2000, Reno, Nevada. 